\section{Rouelle and Chemistry in France}

As interesting paper in Endeavour (July 1953) by Dr. Doug]as McKio deals with Guillaume-François Rouelle (1703-70), demonstrator in chemistry at the Jardin du Roi in Paris, and the teacher of Lavoisier and Diderot. He discusses a. set of notes of Rouelle's lectures belonging to the Science Library of Clifton College, and there is a coloured reproduction of a miniature of Rouelle, also in Clifton College. Dr. McKie points out the importent role which Rouelle took in the development of French chemistry; but in saying that it was he who introduced the phlogiston theory into France, Dr. McKie seems to overlook the account of the theory contained in a two-volume book "Nouveau Cours de Chymie, suivant les Principes de Newton \& de Sthall", published in Paris in 1723, at a time when, Dr. McKie says, Rouelle was still a student.

\section{Watsonia : a Journal of British Botany}

BEGINNING with the first part of Vol. 3 (published December 1953), Watsonia, The Journal of the Botanical Society of the British Isles, now appears in the format of most important scientific journals (obtainable from the Department of Botany, British Museum (Natural History), London; 7s. 6d. per part). The aim of this journal is to provide a medium for the publication of original work on the taxonomy and distribution of flowering plants, vascular cryptogams and charophytes in the British Isles. Included in the present part are contributions relating to Montia fontana, Nuphar intermedia (a presumed relict hybrid), regional variation in Alnus glutinosa, Arctic plants not yet found in Britain, the distribution of Dryopteris Borreri, and notes on Carex flava.

\section{Careers in Agricultural Research}

A USEFUL pamphlet entitled "Careers in Agricultural Research-Training Grants, Studentships and Fellowships awarded by the Agricultural Research Council, 1954" has recently been issued by the Agricultural Research Council. There are openings for research workers in many of the twenty-six agricultural research institutes financed by the State. In addition, certain appointments in universities and other research institutions are financed by the Council ; many of these are temporary in character, but are particularly attractive to the young worker who wishes to work under the personal guidance of a distinguished scientist. The pamphlet also gives useful information about the scientific staffs of the Council and of the State-aided agricultural research institutes, and about the advisory services. This year the Council is again offering two veterinary clinical fellowships to provide opportunities for suitably qualified veterinary clinicians and pathologists of Ph.D. standing to continue research for two or three years. The fellowships will be renewable annually up to a maximum of three years and will carry a stipend of $£ 850$ a year. In addition, the Council is continuing to offer a limited number of junior agricultural research fellowships, carrying a stipend of $£ 630$ a year, to research workers of outstanding ability; and a larger number of postgraduate training grants and research studentships in agricultural and veterinary science. Applications for awards should reach the Council by March 20 . Further information and a copy of the pamphlet can be obtained on application to the Secretary, Agricultural Research Council, Cunard Building, 15 Regent Street, London, S.W.1.

\section{Postgraduate Agricultural Scholarships}

THE three Agricultural Departments of the United Kingdom have been allocated $£ 625,000$ over the next three years from the general allotment of Counterpart Funds given by the United States to Great Britain and other European countries for increasing productivity. It has now been announced that $£ 25,000$ of this sum will be devoted to postgraduate scholarships, the distribution being England and Wales, $£ 15,000$; Scotland, $£ 5,000$; and Northern Ireland,

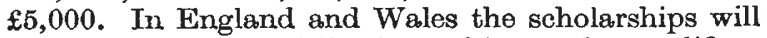
be awarded in the following subjects, the qualifications required being considerably higher than for ordinary postgraduate scholarships: agricultural economics; farm management; estate management; and land economics and land use. Their value will be $£ 400-£ 800$ a year free of income tax plus all compulsory fees, authorized travelling expenses and a book allowance not exceeding $£ 10$ a year. Further information and application forms can be obtained from the Secretary, Ministry of Agriculture and Fisheries, 1-4 Cambridge Terrace, Regent's Park, London, N.W.1.

\section{Australian and United Kingdom Postgraduate Research Studentships tenable in Australia}

To assist in the movement of scientists between various parts of the British Commonwealth, the Australian Commonwealth Scientific and Industrial Research Organization and the Department of Scientific and Industrial Research and the Agricultural Research Council of Great Britain are collaborating in an arrangement for providing a limited number of postgraduate research student. ships tenable at Australian universities or other approved Australian research institutes. Under the arrangement, an allowance of $£ A 600$ a year and other approved expenses in Australia will be made by the Commonwealth Scientific and Industrial Research Organization, and the Department of Scientific and Industrial Research or the Agricultural Research Council, as may be appropriate, will pay travelling expenses to and from Australia. Candidates must be honours graduates in science or agriculture, and must be British subjects normally resident in the United Kingdom. The awards will be tenable for two full years in Australia. Full details regarding the conditions of the studentships are being made available to all departments of the natural sciences and agriculture in universities in the United Kingdom and to technical colleges and polytechnies.

\section{Sixth Commonwealth Entomological Conference, London}

THE sixth Commonwealth Entomological Conference will be held in London during July 7-16, and will be organized by the Commonwealth Institute of Entomology, Liondon. Delegates to the Conference are being nominated by the Governments of the various countries of the British Commonwealth, including many of the Colonial Territories. In addition to the business meetings, which will be attended only by delegates, there will be open moetings on July 8, 9, 12, 13 and 15, at which subjects of wide interest to economic entomologists will be discussed. These open meetings will commence with short papers, read by invitation, the subjects being as follows : recent developments in the use of insecticides on field crops and against 